This is an accepted post-peer-review, pre-copyedit version of the article that will published in Counselling and Psychotherapy Research and may not exactly replicate the authoritative document published in the journal. It is not the copy of record.

\title{
"Everyone should do it": client experience of a 12-week Dialectical Behaviour Therapy (DBT) group programme - an interpretative phenomenological analysis
}

Jasmine Childs-Fegredo ${ }^{\mathrm{a} *} \&$ Lisa Fellin ${ }^{\mathrm{b}}$

${ }^{a}$ Institute of Public Health and Primary Care, University of Cambridge, 18

Trumpington Road, Cambridge, CB2 8AH, U.K

jc2039@cam.ac.uk

$+44(0) 1223465194$

${ }^{b}$ School of Psychology, University of East London, Water Lane, Stratford, London, U.K. l.c.fellin@uel.ac.uk 


\title{
"Everyone should do it": client experience of a 12-week Dialectical Behaviour Therapy (DBT) group programme - an interpretative phenomenological analysis
}

\begin{abstract}
Objective: There is a dearth of practice-based evidence of adapted or 'DBT-informed' transdiagnostic models, which could provide services and clinicians with information of what works and for whom, in which settings. This paper aims to bridge this gap by exploring the client experience of a 12-week transdiagnostic dialectical behaviour therapy (DBT) group programme in a private psychiatric hospital. Method: Five participants with varied clinical diagnoses and previous therapeutic experiences were interviewed following completion of one or more of the same adapted DBT programme, comprising of the standard four modules over 12 weeks, including a weekly skills group and 1:1 therapy. Interpretative phenomenological analysis (IPA) was applied to give voice to the clients' lived experience of the group. Results: Three master themes were identified: 'Pre DBT: Crisis \& Desperation'; 'In-session: Belonging'; and 'The Real World: Living', each characterised by 4 sub-themes, highlighting helpful and hindering factors of clients' current and previous therapeutic experiences. Conclusion: Overall this version of DBT in a transdiagnostic setting was experienced as helpful and positive by participants; main outcomes included being able to build a life worth living, feel hope and joy, build DBT skills into a lifestyle, and develop reflective practice. Implications for clinical practice, service delivery and policy are also discussed. The article aims to provide clinicians with practice-based evidence to inform the delivery of DBT as well as supporting the case for the use of DBT with various disorders, thus paving the way for future research in this area.
\end{abstract}


Keywords: Dialectical behaviour therapy; DBT; interpretative phenomenological analysis; client experience; qualitative research; private healthcare.

\section{Introduction}

Dialectical behaviour therapy (DBT) is a complex psychological intervention developed integrating some of the principles of Cognitive Behavioural Therapy (CBT) with mindfulness-based and systemic strategies. The programme draws on the notion of the biosocial theory (Linehan, 1993), comprising four modules: Mindfulness, Emotion Regulation, Interpersonal Effectiveness and Distress Tolerance (Linehan, 2015). It aims to alleviate clients' difficult lifeworlds by enhancing their skills to deal with disorganised emotions and impulsive behaviours.

There is a dearth of literature on practice-based evidence for DBT, and which components are useful for different client groups (Koerner, 2013; Linehan \& Wilks, 2015). RCTs with follow-ups have proven the efficacy of DBT, finding it uniquely effective in reducing suicide attempts (Linehan et al., 2006; Koons et al., 2001). A Cochrane Review (Stoffers et al., 2012) pulled together research totalling up to 1804 participants in the USA, indicating DBT as the treatment of choice for characteristics associated with borderline personality disorder (BPD), including impulsivity, interpersonal problems, emotion dysregulation, self-harm, and suicidal behaviours. Following empirical evidence reporting successful outcomes, various adaptations of the standard model came to fruition, with the recognition by clinicians that DBT can be tailored to different client groups in various settings (Lungu \& Linehan, 2016; Ritschel, Lim \& Stewart, 2015). Current National Institute for health and Care Excellence (NICE) guidelines (2009) advocate DBT as a treatment of choice for women with a diagnosis of BPD, or for the management of self-harm, and for certain cases of eating 
disorders. There is hence the need for research into delivery of DBT to wider groups. It has also been demonstrated that the client voice and practice-based evidence are pivotal in shaping policy (McLeod, 2011), by exploring how psychological therapies work and for whom.

Adaptations of DBT include DBT for Post Traumatic Stress Disorder (PTSD: Bohus et al., 2013), DBT for the eating disorders (Wisniewski \& Porath, 2015), Radically Open DBT (Lynch, Hempel \& Dunkley, 2015), as well as adaptations for adolescents (Rathaus \& Miller, 2015) and short-term programmes (van den Bosch, Sinnaeve \& Nijs, 2013). All studies show positive effects on suicidal behaviours and Non Suicidal Self Injury (NSSI - including self-harming behaviours such as cutting), as well as studies reporting bespoke benefits with regards to the various diagnoses.

This paper addresses a gap in the literature by giving voice to clients who completed DBT, adapted to a short-term 12 week programme for a transdiagnostic group, at a private psychiatric hospital. Standard DBT is usually one year in duration, comprising of the 4 modules, delivered within a therapeutic framework which contains group skills training, 1:1 therapy, telephone consultations and team consultations.

The DBT programme in the current study comprises all these elements, but is concentrated over 12 weeks, spanning the standard provision of 3 months insurance cover for patients in a private healthcare setting. The aim of the programme is to equip clients with the life skills they need to react differently to self-injurious behaviours and develop insights into interpersonal functioning and relationships.

Our findings will inform mental health practice by providing clinicians with accounts of 
experiences of clients who benefited from short-term DBT in a transdiagnostic setting speaking to the need for ongoing research into the delivery and experiences of adapted versions of the therapy (Ritschel et al., 2015). Furthermore, the identification of helpful and hindering aspects of the therapy (Cooper \& McLeod, 2015) could provide insights to enhance the delivery of the model, through addressing the research question of how clients experience and perceive receiving adapted DBT in a private psychiatric setting.

\section{Method}

Interpretative Phenomenological Analysis (IPA, Smith et al., 2009) was chosen as the methodology for its multi-layered approach combining phenomenology, hermeneutics and ideography. Engagement with phenomenology aims at getting as close as possible to the complexity of participant 'experience'. However, this 'experience' can only be grasped through the double hermeneutics of participant and researcher. IPA been posited as especially suited to studies that aim to relate findings to bio-psycho-social theories that dominate current thinking in healthcare professions (Biggerstaff \& Thompson, 2008) such as DBT's underpinning theory of emotion dysregulation (Linehan, 1993).

\section{Participants}

Four females and one male were recruited from a UK private psychiatric hospital having completed the 12-week adapted DBT programme, where interviews took place. Three participants had completed the DBT programme twice, and two participants had completed the programme just once. Time since completion of the programme varied from 14 months to just one month prior to interview. Participants varied in clinical 
diagnoses (see table 1): three were diagnosed with BPD, one with clinical depression and a comorbid eating disorder, and one with bi-polar affective disorder.

Patients referred by their psychiatrists for an assessment are screened by a DBT therapist for suitability to join the 12-week programme. The DBT assessment includes the client's diagnosis, history of the presenting problem/s, engagement in problem behaviours such as substance use or disordered eating, and readiness for change. Our sample includes participants with a diagnosis of borderline personality 'traits' who completed at least one 12-week DBT programme; no exclusion criteria were based on age, gender, religion, sexual orientation or ethnicity.

\section{Procedure}

The study was approved by the University Ethics Board and the private psychiatric hospital from where participants were recruited, through posters inviting participants to contact the researcher by email. Five suitable participants were invited to the hospital outpatient therapy department or the University site (upon request) for a semi-structured interview built according to IPA guidelines (Smith et. al, 2009).

The main ethical challenge was to avoid causing distress to participants, already presenting with emotion dysregulation; contacts for supportive agencies were given to participants at the end of the interview following a debrief. The interviews were conducted by the first author, a researcher with experience of working on locked wards with other patients diagnosed with BPD and delivering DBT groups in other contexts. This was perceived as a strength to the interview process, whereby signs of distress could be appropriately managed, but also gave rise to concerns of influencing the data. The researcher's engagement with reflexivity ensured that her dual role of 'therapistinterviewer' was carefully considered (Smith et al., 2009). Interviews were audio- 
recorded, and transcribed verbatim and anonymised to protect participants' confidentiality.

\section{Analysis}

Transcripts were transcribed and analysed by the primary researcher following the steps detailed by Smith and colleagues $(2004,2009)$. To enhance validity (Elliott, Fisher \& Rennie, 2013) and rigour (Morse, 2015), triangulation was undertaken, as well as the use of peer consultation and a reflexive journal. The second author independently checked the trustworthiness of the analysis to ensure rigour, and the first author presented and shared the analysis for comment with the London IPA group. Braun \& Clarke (2013) argue that IPA is underpinned by a critical-realist ontology assuming that language reflects a perception of experience requiring a critical approach to interpretation. We adopted this stance to demonstrate how taking a critical-realist approach in an IPA study can add an extra layer of interpretation in analysis. This included drawing on psychodynamic theory such as projective identification (Klein, 1946) to conceptualise interpretation, in a client group prone to projection and thereby influencing the interviewer. This gave rise to subthemes embedded within latent influences.

\section{Reflexivity}

The researcher's engagement in reflexivity has been posited as one way of recognising, at some depth, their influence on the project from inception through to analysis (Shaw, 2010). The dual role of 'therapist-interviewer' was reflected on, aiming to balance our phenomenological stance and position as mental health professionals and researchers. Bracketing (Smith et al., 2009) was endeavoured in the awareness that this past experience will influence the data (Galbusera \& Fellin, 2014), but aiming to create 
space in the interview to allow implicit understandings to be brought forward. The researchers therefore engaged in reflexivity of their own process, bringing awareness to their influence on the data by recursively adjusting ideas in response to subject matter (Larkin et al., 2006).

\section{Interpretative Phenomenological Analysis (IPA)}

Our IPA identified three master themes across participants: 'Pre DBT: Crisis \& Desperation'; 'In-session: Belonging'; and ‘The Real World: Living', characterised by 4 intertwined sub-themes, highlighting helpful and hindering factors of clients' therapeutic experiences (See table 2.0).

\section{Pre DBT: Crisis \& Desperation}

Common to all participants is the pre-DBT sense of having experienced the darker elements of their psyches coupled with the futility of their attempts to reconcile - be that in ineffective treatments, trips around the world, or the desperate search within the mental health system to find an effective intervention; this emerges particularly in the first sub-theme illustrating the difficult diagnostic and therapeutic journey that eventually led them to this treatment: The DBT Pathway.

\section{“When I was assessed I was asked 'why are you here?', because initially I was told that it (DBT) is mostly for people with personality disorders and I don't have a personality disorder" (Rose).}

Whilst transdiagnostic applications of DBT are now disseminated, it is apparent that clinicians in this setting may not have been aware of this, thus impacting the client's sense of belonging, so imbued in the identification with their diagnostic label. Another participant illustrates her experience prior to DBT: 
"There was a CBT session here that I found really useful... about being present. So in the 'now'. And I thought it's fine, I am going to be absolutely fine. I am going to go to India, I am going to learn yoga, and I am going to be in the 'now', and I am going to go surfing... And actually catalysed a total breakdown" (Rachel)

Emma echoes the futility of her experience of cognitive behaviour therapy (CBT) in attempts to deal with her intrusive thoughts:

"I think a lot of the stuff I learnt in CBT, rightly or wrongly, was to try and challenge these thoughts, to try to understand them, to try to change them. But to be honest that quite often led me down an obsessive spiral of just policing my own thoughts and arguing with myself and just getting more and more distressed."

Several participants reported CBT as ineffective and potentially damaging, highlighting a need within services for clients to be signposted to treatment modalities best suited to their needs, irrespective of diagnosis.

The sub-theme Symptoms \& Emotions shows how all participants reported a more prominent symptomology before DBT than after: this ranged from suicidality, alcoholism, major depression, self-harm, anxiety, and intense experience of emotions such as fear and anger, and obsessive-compulsive disorder (OCD) tendencies.

"just before I started (DBT)...I was in such turmoil, erm. But at my worst, I was yeah. Feeling suicidal, I had self-harmed on a number of occasions... hitting myself....Destroying objects...So sort of angry rages."(James). 
Literature highlights that clients enrolled in DBT are often difficult to engage, and dropout rates are high (Gaglia et al., 2013). Participants comment on their suicidal thoughts, relapses and difficulties in symptom management. Engagement is therefore key, and the ambivalence hinders treatment outcome. This tension could be viewed as a spectrum encapsulating the third sub-theme: Ambivalence Vs Commitment. Rachel describes how DBT could be 'sold' to ambivalent clients:

"If it can be sold at the beginning this is not namby pampy therapy, talk to me about your you know, 3 months as a baby, stuff. This is really practical...tangible...rather than necking half a bottle of whiskey a night, because that is not working out so well for you at the moment."

The fourth sub-theme Refuting Insanity, highlights how all participants advocated DBT to others, perhaps in an attempt to destigmatise and normalise themselves and DBT, illustrating it as a very positive growing experience everyone could benefit from, not only people 'who are suffering':

"I think everyone should have DBT, I think it's absolutely brilliant for helping you to be more sympathetic to yourself, and to stop trying to squish yourself into...the person I think I should be." (Rachel)

Rose mirrors this in her account:

"I just think everyone should do it (DBT). It doesn't matter even if you are not suffering with a mental illness, because I just think it's so practical. Because everyone gets down..."

Four participants appeared to have difficulty accepting their own 'madness' at the beginning of the treatment, and often would consider their problems as less severe than 
those of 'mad' people. James explains:

“I think I was expecting to be in there with er...I don't want to be politically incorrect, but people who are evidently 'mad'!... and what I found out was that...on the face of things they were sort of, normal everyday people".

\section{In-Session "Belonging”}

In the second master theme participant accounts describe the importance of belonging, giving rise to engagement with the DBT programme following ambivalence. The process of engagement was encapsulated in the sub-theme, Relief $\&$ Surrendering: whereby the dialectic component of the therapy gave rise to feelings of relief, enabling participants to 'yield' to DBT, having built up trust in the model, the therapists, and the setting.

"I think that sitting around and thinking happy thoughts hasn't worked for me so far. And the relief about DBT is that is seems to be saying, you don't have to sit around thinking happy thoughts, it's ok that you are feeling a bit shit, actually." (Rachel).

This account potentially gives voice to the reasons that CBT may not be as effective for certain individuals, as it urges clients to engage in alternative thinking possibly translating as deficits in character, leading to feelings of shame. Common to all accounts was also the possibility of new friendships, with others who shared a similar lived experience: 
"I think a lot of the people there were struggling with similar issues or had you know, similar ways of viewing said issues... So it sort of felt like a safe place..." (Emma)

This also highlights the nature of transdiagnostic applications of DBT, where clients may not share the same diagnosis, but feel a connection in the way they experience and relate to their distress.

The mindfulness module was described by all participants as a component difficult to grasp:

"mindfulness... I was just like 'what?... this is so shit, what is this?'. And then actually, I remember doing this once, coming out of the session and having a fag, and just actually being mindful. And I was just like, 'oh my god, this actually works!' And I was like, 'oh my god, this is so cool!'

Interviewer: What was that like? To go from 'what's the point of this' to 'oh my god this is so cool'?

Charlotte: It's pretty amazing like, I still like...there will be days where I am like: 'oh my god! I am being mindful'. And it's a really good key to have."

Rachel talks of her initial annoyance of the wise-mind skill:

"State of mind: wise-mind. I found really helpful... Previously this has made me want to scream, and stamp and kill people... Well yes, if I were sitting on a rock, and I had lots of time to stroke my beard and think about these things, then yes, I would act wisely, but I don't!...So 
actually the discussion of wise-mind, acting in wise mind...this is

where the mindfulness came in".

The Learning \& Tailoring sub-theme shows how therapy was experienced by participants as a lifeskills class: they felt empowered by having folders and handouts, and treated as competent and agentic adult learners, rather than mentally ill and passive recipients of treatment. Emma explains how the course-like setup enabled a unique learning experience for developing skills:

“if you didn't fill out your DBT diary or your homework...that would be 'non-compliant' with the DBT course. And so, because you had that external framework in place... you had to be considering them the whole week through."

DBT delivers many skills and participants reveal they felt they could 'tailor' it to suit their needs, again boosting a sense of mastery and initiative:

"I've got a ring binder, oh I bought the ring binder myself! [laughs]. And I really like (it)...gives me a sense of gumption! Like it's not just, I am not just going to sit around and talk about being sad, I am sad, what can I do about it, right! Let's go!" (Rachel)

'Tailoring' also pertained to distress tolerance skills, whereby participants revealed what worked for them and what did not:

“It's like an elastic band to do the 'tinging' thing... Sour sweets, incredible. And...I mean they say like listen to music and stuff like that, but for instance when someone has that instant (to self-harm), I 
don't think people can turn on a CD player, that doesn't work, that's not real life." (Charlotte)

Some felt that skills could be overly complicated with confusion over the terms 'dialectical' and 'validation', alluding to the need of thorough explanation of terms from therapists.

The therapists' skills were experienced positively in all accounts, creating an environment where participants felt comfortable in being both accepted and motivated to change. They were given the freedom to question themselves, the therapy, and the skills taught, as summarised under the Validating \& Debunking subtheme. As James explains:

"they were very skilled... when they kind of sensed that I might be feeling uncomfortable, they would kind of say... 'it's ok, your feelings are valid'...I felt they actually meant it, like they weren't just reading off a script kind of thing."

What the therapists can embody as role models was pivotal to the success of the programme. For Rose, the therapists' self-disclosure was as important as their feedback:

"the therapists would get involved as well, so they would give feedback. And that is really helpful... Because you think, you know all the theory, you know everything, and then when they give their stories, and, they are human after all, you think, well they can do it, why can't we?"

Rose goes on to explain how the therapists' persistence and using the 'why' question helped her debunk beliefs around previous unhelpful behaviours: 
“if someone (a friend) invites me, I won't say no initially, I will say yes and then cancel last minute... (the therapists) use that, 'why why, why do you think that is the case? what are you wanting?' So I think it is more the challenge (by the therapists)."

Emma describes how observing other group members helped her understanding herself:

“when you are able to see those processes in someone else, it's sort of easier to identify when your thoughts inside yourself are being counterproductive or destructive..."

Finally, in the sub-theme Gradual vs Sudden change, participants describe the process of change: a subtle experience, coupled with moments of sudden clarity. James recalls a significant moment for him in relation to seeing all the different explanations offered to him on a handout for self-harming behaviour:

"Hearing that explanation, and seeing that there are potentially different ways, healthy ways to manage those emotions, that, that was quite a significant moment...it was a bit sort of an 'ahh-ha!'. Ok, so that's maybe why I was... (self-harming)..."

Emma describes this in terms of her experience:

"I think it (change) was something more subtle... I didn't have any sort of grand epiphany! I was still self-harming for a fair while after the DBT group it just sort of kept lessening in frequency and intensity until it got to the point where I could just ignore the impulses." 


\title{
The 'Real' World: "Living”
}

This theme encapsulates the lived experience of participants after completing the 12week programme and being finally 'released' back into the 'real-world'. The first subtheme shows how participants adopted DBT as a Lifestyle, a part of themselves, albeit in a conscious or unconscious way. James describes how it became a 'faith', as practising skills is backed up by a new optimistic confidence in neuroplasticity:

"It is more like blind faith really. Yeah. Yeah, I am really putting my faith into what has been told to me... that the brain can be rewired. Yeah. There is evidence to sort of suggest that it can... That does give me some motivation to sort of, practise these skills as much as I can."

For Rose, the process of embedding skills is explicit in terms of what the therapy had offered her, in the hope that it could become more habitual and automatic:

\footnotetext{
"In sessions we would just do one minute of something, and you think god, you can just simply do that... And you think, and that's something that I would like to do, it to come unconsciously in your mind, that is what I would like to do."
}

Rachel goes on to say how this instinctive practice of skills and self-care is now 'part of everything' for her:

\author{
"It is absolutely part of my life. \\ Interviewer: Can you say a bit more about that, how it \\ has...integrated into your life?
}

Rachel: This is part of... I mean. This is part of everything...from basic self-soothe stuff... I bought myself the posh body lotion I really 
like...it's really expensive ...putting something on my scars in a way of saying, that's ok. When things happen at work, trying to, I actively think, 'actually ok, right, this is what has happened, what do I feel? Ok, Ifeel anxious, afraid, angry. Ok. Are those feelings valid? Well, yes. Ok we understand why they are valid, yes, ok. What's a rational response?' and then trying to use a wise mind response... that's a process that I try to do with everything. It doesn't always work. But, that is something, I would never ...even thought of that before."

This novel embodied and mindful awareness resonates in accounts of all participants in their own ways. Charlotte goes further to detail this complex experience:

"the second time I did DBT it really helped, the first time I was so ill, I didn't really understand what I was doing... a second time, you are like, oh ok, you really like, it sinks in more. And you really take it in ...

Interviewer: And in terms of your day-day life, how might DBT have changed things for you?

Charlotte: I think it did, it probably does help, day-day... But I think it's not just that. It's my lifestyle, and maybe it helped me how I see things now, my outlook and things.

Interviewer: such as?

Charlotte: I dunno. I actually look at whether the weather is sunny today or, do you know... Whereas I would be so in my head and not even give a shit about what the weather was. I would be thinking, oh 
my god, like, what's everyone looking at me, why is everyone...

Whereas I wouldn't even take in things, like, 'oh the weather is really nice', 'oh this smells different'. So I think it has helped me on that level."

Charlotte is able to see things in a simplistic way reaping benefits by being grounded in the world around her, as opposed to an idealistic view of what it may have meant to incorporate DBT into her lifestyle and outlook.

There is a sense throughout all accounts of an onward struggle, but one that is full of life, of 'living' and being in the world, which is full of Hope \& Joy, as characterised in the second sub-theme.

Rachel tells how seeing herself differently brings about positive emotions:

Interviewer: So DBT has helped you look at yourself differently?

Rachel: Yes, I am not disgusting and I am not abnormal.

Interviewer: Ok, so how does it feel to say that as opposed to what you would have said...

Rachel: [laughs] Gleeful. I think because it is still quite a new feeling it's glee. I have had (a lifetime) of... And don't get me wrong, it's not plain sailing.

She has worked incredibly hard to achieve this, and it is still not easy, but that she can use the skills of observing her emotions non-judgementally in order to feel positive emotions, as well as more painful ones. James says: 
"I sort of reached a point where... began feeling... contentment, or actually enjoying life. So yeah, I guess that dawned on me slowly but surely."

The 'dawning' is revealing of something fresh, new and previously unknown. It instils hope that more is on offer in life, in the wake of a painful and tormenting journey through the darkness.

In contrast to the need to 'refute insanity' pre-DBT, participants revealed a new active engagement with the self, with less extreme black-or-white emphasis. Previously, they intolerantly questioned the self, in a relentless battle with objective views on what it meant to be 'normal'.

"When I was in here...we were in the canteen, and (my friend) said, it's scary, cos you look around and everyone looks normal. And I was like, they are normal! We are normal... I mean, my previous idea of what was normal and what I had to be and think and feel was so harmful. So harmful." (Rachel).

There is a sense that she has shifted from resisting being 'madly-sane' to accepting herself as 'sanely-mad', having deconstructed harmful rhetoric. This enables space for a subjectivity, which previously had to be refuted through fear of shattering the falseself, built up in phantasy (Winnicott, 1965) and based on societal constructs.

\section{Discussion}

This study aimed at understanding and giving voice to the client experience of an adapted DBT programme, thereby providing clinicians with practice-based evidence to inform the delivery. Building on qualitative studies on client experience focused on 
DBT for BPD specifically, or in community settings (Cunningham et al., 2004;

Hodgetts et al., 2007; McSherry et al., 2012; Perseius et al., 2003), Our study is the first attempting an in-depth inquiry into a transdiagnostic, DBT-informed programme in a private setting, and furthermore, with a focus on perceived change. Research to date has suggested that change processes should be specified at the level of the client, therapist and service delivery setting, in order to improve outcomes in DBT (Koerner, 2013). Implications for policy are discussed, where a sufficiently robust evidence base is now available to inform guidelines for disseminating DBT to wider groups.

\section{Synthesising the DBT Experience}

The experience of DBT for all participants began with tumultuous emotions and symptomology, ranging from suicidal and impulsive behaviours, to more complex underlying emotion dysregulation. The 'pathway to surrender' seems to emerge through mindfulness, group cohesion and validation. By the end of the 12 week programme, all participants had experienced shifts in symptoms, which is in line with literature advocating DBT's efficacy (Stoffers et al., 2012). Participants' voice sheds light on how this experience was perceived overall.

DBT skills specifically mentioned as helpful were self-soothing, distress tolerance techniques (such as eating a sour sweet or biting a chilli), acting opposite, and developing mindfulness practice. The key concepts found helpful were validation, radical acceptance, using the wise-mind approach, and being allowed the flexibility to tailor the skills to meet their needs. However, in accordance with McSherry et al. (2012) who reported participants finding theoretical concepts difficult to grasp, some constructs (e.g. 'dialectical' and 'validation') seemed overly complex or alienating. The therapists' flexible approach seems to harness this process, by allowing clients to come 
up with their own terminology with the freedom to criticise, but not refute, the concepts completely.

\section{Potential harm through other treatment models}

Another interesting finding in this study was the participants' responses to other forms of therapy, most notably, CBT. Focus on previous treatment modality was not central to our research or interview questions, but came up in four of the individual participant accounts when talking about their therapeutic journey. These participants described CBT as either unhelpful to potentially damaging. Whilst much of the pro-DBT literature would recommend the DBT model over CBT for those diagnosed with BPD (Linehan \& Wilks, 2015), few studies report potential harm to clients engaging in CBT. However, one participant who received CBT for eating disorders found it helpful to some extent. Our study is consistent with Haeffel's (2010) research into cognitive skills training underscoring the importance of identifying individual difference variables that moderate or even hinder intervention efficacy.

Future research could look at participant experience and outcome of CBT for clients with NSSI, emotional dysregulation and impulsivity. Our small sample size does not allow generalisation of this client experience, but such a finding should be further explored in research and practice, due to the ethical dilemmas arising from it.

\section{The role of the therapists}

Koerner (2013) surmised that little is known to date about what therapists must know and do to get good outcomes in DBT. The therapists' approach was deemed important in creating a validating environment for participants: it was experienced as genuine, with no reading from scripts. The therapists were perceived as well-trained, with the 
ability to hold the group and psychopathology of individual clients. The creation of core conditions using empathy, acceptance, validation, in a holding and supportive environment, meant that clients were able to feel safe and 'surrender' to the therapeutic process. It is therefore possible to conclude that therapist training and expertise was perceived as important in providing an environment which facilitated a strong therapeutic alliance (Duncan, 2014). This was achieved with constant check-ins by the therapists with group members, remembering the clients' individual backgrounds and needs, feeding back to clients about their contributions, validating, and allowing clients to challenge within the boundaries of the therapeutic environment. The result was a client group willing to engage, interact, learn, and tailor therapy to suit their needs.

\section{Therapist Self-Disclosure}

The therapists were perceived as part of a team of 'leaders' which also added to the trusting dynamic and sense of cohesion. Furthermore, the therapists used selfdisclosure, which was positively received: this enabled a more transparent and humanistic stance (Audet \& Everall, 2010). Overall, the therapists' stance fostered a trusting therapeutic alliance, a key element in client recovery (Horvath, 2001), which has implications for DBT delivery regardless of adaptation or setting.

\section{Application of DBT to a transdiagnostic group}

Two participants did not have a full BPD diagnosis - they were accepted onto the programme based on their emotion regulation skills, impulsivity and substance use. The group cohesion could be ascribed to these similar ways of experiencing and expressing their distress. Our study questions diagnostic criteria as a pathologising prerequisite necessary in the healthcare system, whereby a descriptive diagnosis, should perhaps not be the only means of signposting clients to a treatment (Khoury et al.,2014). DBT 
seems to rely on effective and accurate case conceptualisation strategies that allow therapist and client to collaboratively address multiple diagnostic and quality-of-life related issues (Ritschel et al., 2015). Indeed, DBT is not strictly targeted for BPD clients, but for those who could benefit from the model and those labelled in the psychiatric community as 'difficult to treat' (Linehan \& Wilks, 2015).

All participants valued the opportunity to make friends with others experiencing similar impulsivity or emotion dysregulation, and to find space for intimacy and connection. This highlights the importance of signposting clients to treatments based on their personality characteristics, as opposed to diagnosis. This study would advocate assessments, as described by participants, as focussing on emotion dysregulation, problem behaviours, impulsivity, substance use or 'neuroticism' (Barlow et al., 2014). Moreover, our findings call for further research into the application of DBT with transdiagnostic groups.

\section{Adapted DBT}

The current study focused on a 12-week adapted programme whereby the therapists role-modelled a flexible approach to the treatment. It is hence a 'DBT-informed' therapy (Dimeff et al., 2007), rather than standard DBT. DBT was previously adapted as a 12-week programme, but for adolescents requiring a less intense commitment (Rathaus et al., 2015), or for inpatient setting (Kroger et al., 2006). Future research could aim to pacify debates around correct adoption of terminology of treatment models, so that more clarity is achieved in the field, as opposed to creating divisions between 'DBT purists' and others using flexible adaptations (Pederson, 2015). 
It is also worth noting that several participants re-took the 12 week programme, feeling that the skills required a longer therapeutic input to understand and embed. This treatment length was tailored to the private healthcare system, where most insurances cover patients for a stay of 12 weeks. It is therefore difficult in this study to determine whether the 12 weeks was perceived as an overall positive of the programme or influenced by other factors. Literature suggests that clients do benefit from short interventions (van den Bosch et al., 2013), but further research is necessary to ascertain which treatment durations work and for whom.

Participants valued the opportunity to learn from more 'experienced' group members, highlighting the importance of running open groups. This aided in the 'rabbit in the headlights' experience upon joining a DBT group, enabling a learning environment to be cultivated whereby peer learning was key : through the verbal ideas of how to manage distress such as distress tolerance techniques, opportunities for altruism by giving ideas or objects to other group members, and learning from the process of others. Witnessing the process of others in the group provided a powerful learning curve becoming a spectator to their own psychological and emotional processes. This factor was perceived as helpful in the process of change, providing participants with a mirror into their own dysfunctional and destructive processes and enabling them to make real life changes (Higginson \& Mansell, 2008).

In summary, this particular DBT-informed programme is a good example of how the model can be adapted to a more client-friendly and cost-effective delivery.

Assessments prior to adapting DBT are necessary within services, could ascertain which facets of the standard model are necessary to treat the client group, alongside good rationale for adaptation (Swales et al., 2000). 


\section{Limitations}

Whilst a small sample size is not a limitation in qualitative research (Smith, 2011), as this enables more attention to the ideographic nature of the accounts with an in-depth inquiry into rich data, further studies are needed to ensure additional contribution to the field, involving other client groups and contexts.

The homogeneity and heterogeneity of the sample also needed consideration. The sample is homogenous in the sense that it represents a group of people who took the same DBT programme in the same context, with the same facilitators, having been through the same assessment. Diagnostically it was heterogeneous, representing a variety of diagnoses, as well as some participants having completed the programme more than once. As opposed to limiting the analysis, the heterogeneity of the sample provided this study with possibilities of understanding more about the experiences of hard-to-reach clients, with a range of histories with psychiatric services and of differing diagnoses. This enables a fuller picture to be captured for dissemination to various audiences. Furthermore, the very specific way in which DBT has been adapted in this setting could inspire further research into how and to whom DBT can be adapted, including homogeneous groups.

\section{Implications for policy}

The Cochrane review (Stoffers et al., 2012) recommends DBT as the treatment of choice for BPD in the USA, whilst the NICE guidelines in the UK recommend DBT for women with history of recurrent self-harm. This policy could be deemed rather thin, given the evidence base for DBT as an effective intervention, not only for BPD but for other client groups. Whilst our sample cannot claim to represent all transdiagnostic groups, it builds on current literature in support of DBT for various diagnoses (Ritschel et al., 2015). DBT is rather costly as a full 12-18 month programme - evidence based 
shorter versions could provide services with cost-effective programmes deliverable to wider groups. 
Audet, C.T., \& Everall, R.D. (2010). Therapist self-disclosure and the therapeutic relationship: a phenomenological study from the client perspective. British Journal of Guidance \& Counselling, 38(3), 327-342.

Barlow, D. H., Sauer-Zavala, S., Carl, J. R., Bullis, J. R., \& Ellard, K. K. (2014). The Nature, Diagnosis, and Treatment of Neuroticism: Back to the Future. Clinical Psychological Science, 2(3), 344-365.

Biggerstaff, D. \& Thompson, A. (2008). Interpretative phenomenological analysis (IPA): a qualitative methodology of choice in healthcare research. Qualitative Research in Psychology, 5, 173-183.

Bohus, M., Dyer, A., Priebe, K., Kroger, A., Kleindienst, N., Schmahl, C., \& Steil, R. (2013). Dialectical behaviour therapy for post-traumatic stress disorder after childhood sexual abuse in patients with and without borderline personality disorder: A randomised controlled trial. Psychotherapy and Psychosomatics, 82(4), 221-233.

Braun, V. \& Clarke, V. (2013). Successful Qualitative Research: A Practical Guide for Beginners. London, Sage.

Cooper, M., \& McLeod, J. (2015). Client helpfulness interview studies: A guide to exploring client perceptions of change in counselling and psychotherapy. (Working paper). Retrieved from https://www.researchgate.net/profile/Mick_Cooper

Cunningham, K., Wolbert, R., \& Lillie, B. (2004). It's about me solving my problems: Clients' assessments of dialectical behaviour therapy. Cognitive and Behavioural Practice. 1(2), 248-256.

Dimeff, L., Koerner, K., \& Swenson, C. (2007). Adopt or adapt? Fidelity Matters. In Koerner, K. \& Dimeff, L. (Eds.), Dialectical Behavior Therapy in Clinical Practice: Applications across disorders and settings (pp. 19-36). New York: The Guildford Press.

Duncan, B.L. (2014). Becoming a better agency. In On becoming a better therapist: Evidence-based practice one client at a time (2nd ed.) (pp. 191-215). Washington, DC: American Psychological Association.

Elliott, J., Fischer, C., \& Rennie, D. (1999). Evolving guidelines for publication of qualitative research studies in psychology and related fields. Journal of Clinical Psychology, 38, 215-29. 
Gaglia, A., Essletzbichler, J., Barnicot, K., Bhatti, N., \& Priebe, S. (2013). Dropping out of dialectical behaviour therapy in the NHS: the role of care coordination. The Psychiatrist, 37, 267-271.

Galbusera, L. \& Fellin, L. (2014). The intersubjective endeavour of psychopathology research: methodological reflections on a second-person perspective approach. Frontiers in psychology, 5, 1150.

Haeffel, G.J. (2010). When self-help is no help: Traditional cognitive skills training does not prevent depressive symptoms in people who ruminate. Behaviour Research and Therapy, 48(2), 152-157.

Higginson, S., \& Mansell, W. (2008). What is the mechanism of psychological change? A qualitative analysis of six individuals who experienced personal change and recovery. Psychology and Psychotherapy, 81(3), 309-328.

Hodgetts, A., Wright, J., \& Gough, A. (2007). Clients with borderline personality disorder: Exploring their experiences of dialectical behaviour therapy. Counselling \& Psychotherapy Research, 7(3), 172-177.

Khoury, B., Langer, E. J., \& Pagnini, F. (2014). The DSM: Mindful science or mindless power? A critical review. Frontiers in Psychology, 5(602), 1-8.

Klein, M. (1946). Notes on some schizoid mechanisms. International Journal of Psychoanalysis, 27, 99-110.

Koerner, K. (2013). What must you know and do to get good outcomes with DBT? Behavior Therapy, 44(4), 568-579.

Koons, C., Robins, C., Lynch, T. (2001) Efficacy of dialectical behaviour therapy in women veterans with borderline personality disorder. Behavior Therapy, 32, 371-390.

Kroger, C., Schweiger, U., Sipos, V., Arnold, R., Kahl, K.G., Schunert, T., \& Reinecker, H. (2006). Effectiveness of dialectical behaviour therapy for borderline personality disorder in an inpatient setting. Behaviour Research and Therapy, 44(8), 1211-1217.

Larkin, M., Watts, S., \& Clifton, E. (2006). Giving voice and making sense in interpretative phenomenological analysis. Qualitative Research in Psychology, $3(2), 102-120$. 
Linehan, M. (2015). DBT skills training manual (2nd ed.). New York: The Guilford Press.

Linehan, M. (1993). Cognitive-behavioural treatment of borderline personality disorder. New York: Guilford Press.

Linehan, M., Comtois, K., Murray, A., Brown, M., Gallop, R., Heard, H., Korslund, K., Tutek, D., Reynolds, S., \& Lindenboim, N. (2006). Two-year randomized controlled trial and follow-up of dialectical behavior therapy vs therapy by experts for suicidal behaviors and borderline personality disorder. Archives of General Psychiatry. 63(7), 757-66.

Lungu A. \& Linehan, M (2016) Dialectical behavior therapy: A comprehensive multiand transdiagnostic intervention. The Oxford handbook of cognitive and behavioral therapies, 200

Linehan, M., \& Wilks, C.R. (2015). The course and evolution of dialectical behavior therapy. American Journal of Psychotherapy, 69(2), 97-110.

Lynch, T.R., Hempel, R.J., \& Dunkley, C. (2015). Radically open-dialectical behavior therapy for disorders of over-control: Signaling matters. American Journal of Psychotherapy. 69(2), 141-62.

McLeod, J. (2011). Developing and delivering practice-based evidence. A guide for the psychological therapies. Counselling and Psychotherapy Research, 11(1)

McSherry, P., O’Connor, C., Hevey, D., \& Gibbons, P. (2012). Service user experience of adapted dialectical behaviour therapy in a community adult mental health setting. Journal of Mental Health, 21(6), 539-547.

Morse, J.M. (2015). Critical analysis of strategies for determining rigor in qualitative inquiry. Qualitative Health Research, 25(9), 1212-1222.

National Institute of Clinical Excellence (NICE). (2009). Borderline Personality Disorder: Recognition and Management. NICE Guidelines [CG78]. Retrieved from: https://www.nice.org.uk/guidance/cg78/chapter/1-Guidance

Pederson, L.D. (2015). Dialectical behaviour therapy: A contemporary guide for practitioners. Sussex, UK: John Wiley \& Sons Ltd.

Perseius, K.I., Öjehagen, A., Ekdahl, S., Åsberg, M., \& Samuelsson, M. (2003). Treatment of suicidal and deliberate self-harming patients with borderline 
personality disorder using dialectical behavioral therapy: The patients' and the therapists' perceptions. Archives of Psychiatric Nursing, 17(5), 218-227.

Rathus, H., \& Miller, L. (2015). DBT skills manual for adolescents. New York: Guildford Publications Inc.

Ritschel, L.A., Lim, N.E., \& Stewart, L.M. (2015). Transdiagnostic applications of DBT for adolescents and adults. American Journal of Psychotherapy, 69(2), 111-128.

Shaw, R.L. (2010). Embedding reflexivity within experiential qualitative psychology. Qualitative Research in Psychology, 44, 233-243.

Smith, J.A. (2011). Evaluating the contribution of Interpretative Phenomenological Analysis. Health Psychology Review, 5(1), 9-27.

Smith, J.A. (2004). Reflecting on the development of Interpretative Phenomenological Analysis and its contribution to qualitative research in psychology. Qualitative Research in Psychology, 1, 39-54.

Smith, J.A., Flowers, P., \& Larkin, M. (2009). Interpretative Phenomenological Analysis: theory, method and research. London: Sage.

Stoffers-Winterling J.M., Völlm B.A., Rücker G., Timmer A., Huband N., \& Lieb K. (2012). Cochrane Review. Psychological therapies for borderline personality disorder. Retrieved from http://www.cochrane.org/CD005652/BEHAV_psychological-therapies-forborderline-personality-disorder

Swales, M., Heard, H.L., Mark, J., \& Williams, G. (2000). Linehan's dialectical behaviour therapy (DBT) for borderline personality disorder: Overview and adaptation. Journal of Mental Health, 9(1), 7-23.

van den Bosch, L.M.C., Sinnaeve, R., \& Nijs, M. (2013). Short-term dialectical behaviour therapy for borderline personality disorder. Tijdschrift Voor Psychiatrie, 55(3), 165-75.

Winnicott, D. W. (1965). "Ego distortion in terms of true and false self". The Maturational Process and the Facilitating Environment: Studies in the Theory of Emotional Development. New York: International Universities Press, Inc: $140-57$.

Wisniewski, L., \& Ben-Porath, D.D. (2015). Dialectical behavior therapy and eating disorders: The use of contingency management procedures to manage dialectical dilemmas. American Journal of Psychotherapy, 69(2), 129-140. 
Table 1. Participant Demographics

\begin{tabular}{|c|c|c|c|c|}
\hline \# & Alias & Diagnosis & $\begin{array}{l}\text { Times completed } \\
12 \text { week adapted DBT }\end{array}$ & History Prior to DBT \\
\hline 1 & James & BPD & 1 & $\begin{array}{l}\text { Addiction treatment \& 1:1 } \\
\text { (private) }\end{array}$ \\
\hline 2 & Emma & BPD & 1 & CBT (NHS) \& inpatient (private) \\
\hline 3 & Rose & Depression & 2 & $\begin{array}{l}\text { CBT for Eating Disorders \& 1:1 } \\
\text { (NHS) }\end{array}$ \\
\hline 4 & Charlotte & Bi-polar & 2 & Inpatient/outpatient (private) \\
\hline 5 & Rachel & BPD & 2 & $\begin{array}{l}\text { Pharmacological; some CBT } \\
\text { (private) }\end{array}$ \\
\hline
\end{tabular}


Table 2. Table of Themes

\begin{tabular}{|c|c|}
\hline Master theme & Sub-theme \\
\hline 1. Pre-DBT: 'Crisis \& Desperation' & $\begin{array}{l}\text { - The DBT Pathway } \\
\text { - Symptoms \& Emotions } \\
\text { - Ambivalence v Commitment } \\
\text { - Refuting insanity }\end{array}$ \\
\hline 2. In Session 'Belonging' & $\begin{array}{l}\text { - } \text { Relief \& Surrendering } \\
\text { - } \quad \text { Learning \& Tailoring } \\
\text { - } \quad \text { Validating \& Debunking } \\
\text { - } \quad \text { Sudden v Gradual Change }\end{array}$ \\
\hline 3. The Real World 'Living' & $\begin{array}{l}\text { - } \text { DBT as a lifestyle } \\
\text { - } \text { Reflective Practice \& Spirituality } \\
\text { - Hope \& Joy } \\
\text { - } \text { Objective to the subjective self }\end{array}$ \\
\hline
\end{tabular}


Table 3. Helpful \& Unhelpful aspects of the therapy (Cooper \& McCleod, 2015)

\begin{tabular}{|c|c|c|}
\hline & Helpful & Unhelpful \\
\hline The Therapists & $\begin{array}{l}\text { - Assess according to transdiagnostic } \\
\text { - } \text { application } \\
\text { - Cheate core conditions, enabling belonging } \\
\text { - Validate emotions } \\
\text { - Give } \\
\text { - Challenge / allow to be challenged } \\
\text { - Educate the clients } \\
\text { - Self-disclose } \\
\text { - Balance acceptance and change } \\
\text { - Treat clients as adult learners } \\
\text { - Question the clients' experience } \\
\text { - Use the 'why' question to drill down }\end{array}$ & $\begin{array}{l}\text { - Reading off scripts } \\
\text { - Failing to check } \\
\text { understanding of } \\
\text { difficult } \\
\text { terminology }\end{array}$ \\
\hline The clients & $\begin{array}{l}\text { - Understand \& feel understood } \\
\text { - Commit / surrender to the therapeutic } \\
\text { process } \\
\text { - Do homework } \\
\text { - Learn skills - Mindfulness; self-soothing; } \\
\text { - } \text { radical acceptance; wise mind } \\
\text { Distress tolerance techniques - elastic band, } \\
\text { sour sweets, cold showers }\end{array}$ & $\begin{array}{l}\text { - Disruptive clients } \\
\text { - CBT skills } \\
\text { - Unrealistic distress } \\
\text { tolerance skills e.g. } \\
\text { listening to music }\end{array}$ \\
\hline
\end{tabular}




\begin{tabular}{|c|c|c|}
\hline & $\begin{array}{l}\text { - } \text { Learn from others } \\
\text { - } \text { Make friends - especially during breaks } \\
\text { - Tailoring the therapy } \\
\text { - } \text { Development of reflective practice } \\
\text { - Explore the self / the selves } \\
\text { - Enjoy less pressure in a group setting }\end{array}$ & \\
\hline The setting & $\begin{array}{l}\text { - } \text { Transdiagnostic group } \\
\text { - } \text { Private referral process } \\
\text { - } \text { Rolling group } \\
\text { - Calm surroundings/gardens } \\
\text { - } 12 \text { weeks - adapted DBT }\end{array}$ & \\
\hline The outcome & $\begin{array}{l}\text { - } \text { Develop insight \& spirituality } \\
\text { - } \text { Acceptance of the subjective self } \\
\text { - } \text { - } \text { - } \text { Expel relief } \\
\text { - } \text { Gradual \& sudden change } \\
\text { - } \text { DBT as a lifestyle } \\
\text { - } \text { Compassion for self \& others } \\
\text { - } \text { Curiosity of the self, the world \& others } \\
\text { - } \text { New friendships } \\
\text { - } \text { Feel hope and joy }\end{array}$ & $\begin{array}{l}\text { - Loss of the therapy } \\
\text { setting }\end{array}$ \\
\hline
\end{tabular}

